by applying that abstract universal and necessary law to such things as "terms," we see that a term applicable to anything cannot at the same time be the very opposite.

Mr. Dixon says : "If anyone chooses to say a thing both "is" and 'is not,' there is no law against his doing so, only if he does so he is not talking the Queen's English." But by so doing he breaks the law of reason, if not the law of the land; and, indeed, to act on such a principle when on oath in a court of law might, after all, have inconvenient consequences.

My critic is obliging enough to say in plain and simple terms : "Dr. Mivart is wrong in speaking of the objective absolute validity of the law of contradiction." To this I might content myself by replying: "Quod gratis asseritur gratis negatur"! But let us avoid the use of the terms " is" and "is not": they are not necessary for my purpose. Does Mr. Dixon really doubt whether, if he had lost one eye, he would still remain, after that loss, in the very same condition he was in before? If anyone does not see the objective impossibility of such a thing everywhere and cverywhen-i.e. if he does not apprehend the application of the law of contradiction-then he either does not understand the question, or his mental condition is pathological. The implications of science are implied. Men may pretend to doubt them, their own existence, or the objectivity of mathe matical truths. But their practice shows their unfailing confidence in them on each occasion as it arises-as when cheated by false accounts, personally injured, or engaged in scientific research. When we enter the laboratory, we leave these follies outside.

Hurstcote, December 22, $189 \mathbf{I}$.

St. George Mivart.

WILL you allow me to say a few words in reference to four points in Mr. E. T. Dixon's indictment (NATURE, December IO, p. I25) of Mr. St. George Mivart ?

(I) Mr. Dixon asserts that the law of contradiction "is not a necessary truth at all, it only expresses a verbal convention"it "never tells us whether anything 'is 'or 'is not.' It only informs us that the terms 'is' and 'is not' are not applicable to the same thing." But though it may be only a "verbal convention" that in "the Queen's English" not is the sign of negation, it is not a mere verbal convention that if $a$ signifies the negation of $\mathrm{A}$ (whatever A may stand for), then $\mathrm{A}$ and $a$ "are not applicable to the same thing"-as the law of contradiction asserts, and as Mr. Dixon himself allows. A highly abstract law that is concerned with the relations of propositions cannot, of course, tell us whether any particular thing exists or not--but then no one has ever expected that it should; and moreover, assertions (or denials) of the "existence" of particular objects are not the only "real" propositions (Mr. Dixon appears to be misled here partly by the ambiguity of $i s$ ).

(2) Mr. Dixon says that the law of gravitation-like other laws suggested by particular experiences-depends ultimately upon induction per enumerationen simplicem; that is, upon an inference of the form This $A$ is $X$, that $A$ is $X$, soc. (= Some $A$ 's are $X$ ), $\therefore$ All $A$ 's are $X$ (for we can make nothing better out of an induction by simple enumeration). But this inference is merely an immediate inference, and moreover an illegitimate one; hence, according to Mr. Dixon's view, inductions have no logical justification whatever.

(3) Further, Mr. Dixon asserts that "the supposed peculiar certainty of mathematical conclusions is solely due to the fact that they are truisms," or " purely verbal assertions,"-by which I understand him to mean definitions. In answer to this I should maintain that the peculiar certainty of mathematical propositions, and the fact that here, by help of a single instance, we unhesitatingly conclude to the universal, are (as I have observed elsewhere) explicable by "the consideration that we here see at once the connection, which in other cases we believe on grounds very different from a perception of self-evident interdependence of attributes. When the equality of the interior angles of any one triangle to two right angles has been demonstrated to us, we infer without a moment's doubt that the same relation of equality may be asserted of the interior angles of every triangle; and this because we have seen that with the attributes signified by 'the interior angles of a triangle' there is bound up the attribute of 'being equal to two right angles.' We believe that, if a certain amount of arsenic has on some occa sions produced death, it will always produce death, on the ground that the apparent likenesses are connected with unapparent likenesses; but we have not seen in this case (as we have in the case of the triangle) that there is a self-evident interdependence. And here we see why it is that, in the case of mathematical inductions, we do not need to use Mill's "Inductive Methods.'",

(4) When Mr. Dixon goes on to say that, "if the inhabitants of the Dog Star defined 'twice,' 'two,' and 'four' as we do, then 'twice two' would be to them 'four'; but to say that it was so could only give verbal information," he may be refuted out of his own mouth. For he goes on to remark that, "if the people in the Dog Star chose to define four as $\mathbf{I}+\mathbf{I}+\mathbf{I}$, the socalled 'necessary truth' would not even be true!"; thus showing clearly that it is the facts signified, and not the words which signify them, that we are concerned with. According to $\mathrm{Mr}$. Dixon, it would be (for me) a necessary truth that I have a headache, or am writing with a lead-pencil; while mathematical truths, in as far as "real," are obtained by induction, and are therefore not necessary. I hold, on the contrary, that mathematical truths, though obtained by induction, are "necessary" - that is, true under all circumstances-and that it is only by a confusion between " necessary" and "certain" that a statement of the apprehension of present fact can be called a "necessary truth."

Cambridge, December 14, I891.

\section{Supernumerary Rainbows observed in the Orkneys.}

I INCLOSE a letter just received. The writer has charge of the anemometer formerly kept by the late Dr. Clouston. Dr. Clouston first drew my attention to the extraordinary bow seen at Kirkwall in $187 \mathrm{I}$. My note is in the Quarterly Journal of the Meteorological Society, vol. i. p. 237.

Meteorological Office, 63 Victoria Street, S.W., December $3 \mathrm{I}$, $189 \mathrm{I}$.

Deerness Public School, Kirkwall, December 28, I89I.

SIR, - On reading your very interesting workion "Elementary Meteorology," I find, on p. 20x, reference made to "an extraordinary bow" which appeared at Kirkwall, November I3, I87 I, which you explain by the reflection of the sun's rays from a water surface.

On Saturday, the 26th inst., at 3.20, when the sun was on the horizon, I saw a very distinct rainbow; there was no trace whatever of the secondary bow, but between where it ought to have been and the primary one there were several patches of what are called "supernumerary" bows. The only colour I saw distinctly was the red.

This lasted for about four minutes, when, finally, a second bow appeared just inside the primary, with the colours arranged as in the primary-not reversed, as the secondary. The space between the violet of the primary and this one was almost nil. The red next the violet of the primary was about as distinct as that of the primary. The orange and yellow were distinct also, but the others could hardly be seen. This was, no doubt, owing to the fading light of day, and to the dark colour of the clouds in the north-east, where the bows appeared. These lasted distinctly and complete for about one minute. The bows formed, as is well known, half a circle. The sun was setting behind land at the time, and the wind was blowing at the rate of forty-five miles, so that there could be no water reflection.

If I am not troubling you too much, would you kindly say if this is unusual, and if caused by the "interference" of rays? Yours respectfully, (Signed) M. SpENCE.

\section{Aurora Bंorealis.}

A FINE display of aurora was observed here on the evening of January 4. A faint northern glow was seen at 8.30, which quickly grew in brightness, and at 8.45 , streamers in great quantity were visible. At 9 these became tinted with glowing red on their upper [portions. After exhibiting lively motions for a quarter of an hour or so, the phenomenon settled down into a brilliant and steady arch of light, red on the outside and white within, resting on what appeared to be a bank of dark cloud. By eye estimate this arch would extend about 90 along the horizon, its apex over the north-north-west from $25^{\circ}$ to $30^{\circ}$ in height. The glow was still visible at ro p.m., though considerably diminished in intensity. During the whole of the day a dry and frosty north-west wind prevailed, and the temperature at 10 p. m. was $28^{\circ}$.

Driffield, East Yorkshire, January 5.
J. LOVEL.

NO. I I 58 , VOL. 45] 